Ebisu Ebisu

Études japonaises Études japonaises

48 | automne-hiver 2012

Naissance d'une revue féministe au Japon : Seitō

(1911-1916)

\title{
Introduction. Féminisme et genre au Japon
}

Feminism and gender in Japan

\section{Christine Lévy}

\section{(2) OpenEdition}

1 Journals

Édition électronique

URL : http://journals.openedition.org/ebisu/568

DOI : 10.4000/ebisu.568

ISSN : 2189-1893

Éditeur

Institut français de recherche sur le Japon à la Maison franco-japonaise (UMIFRE 19 MEAE-CNRS)

Édition imprimée

Date de publication : 1 septembre 2012

Pagination : 7-27

ISSN : $1340-3656$

\section{Référence électronique}

Christine Lévy, «Introduction. Féminisme et genre au Japon », Ebisu [En ligne], 48 | automne-hiver 2012, mis en ligne le 21 mai 2014, consulté le 10 décembre 2020. URL : http:// journals.openedition.org/ebisu/568; DOI : https://doi.org/10.4000/ebisu.568 


\section{Introduction}

\section{Féminisme et genre au Japon}

L'année 2011 vit le centenaire de la création de Seitō 青鞜 (Les Bas-bleus), la première revue littéraire créée uniquement par des femmes ${ }^{1}$. Le nom de la revue, publiée par l'association Seitōsha 青鞜社 fondée en juin 1911, est une traduction en sino-japonais de Bluestockings, qui désigne les membres du célèbre salon littéraire présidé par Elizabeth Montagu (1720-1800) à Londres $^{2}$. La revue naquit sous les auspices de l'apparition de la « femme nouvelle ", objet de représentations fantasmées diverses, symbolisant l'entrée des femmes dans la modernité. Les articles publiés dans ce dossier sont issus en grande partie des journées d'étude «Autour du centenaire de Seitō", organisées à la Maison franco-japonaise en septembre 2011.

1. La première présentation en français se trouve dans l'ouvrage de Claire Dodane (2000: 232-247).

2. La première traduction de cette expression en japonais se trouve dans un article qui parle de sa traduction en France, «Bas-bleus " (traduit par «tabi bleus » kontabi 紺足袋) dans un article de journal qui date du 29 juin 1880 (Yübin höchi shinbun 郵便報知新聞). L'auteur explique qu'en France cette expression désigne les femmes qui revendiquent l'égalité des droits avec les hommes, et précise qu'il ignore d'où vient cette expression. En 1888, dans un dictionnaire anglais-japonais (Eiwa shinkokumin daijiten 英和新国民 大辞典), on trouve une autre traduction à l'entrée Bluestocking : bungaku aru onna 文学 アル女 (une femme instruite). Voir l'article de Watanabe Mami (2011 : 33-48). 
Publiée régulièrement de septembre 1911 à février 1916 tous les premiers du mois ${ }^{3}$, Seitō devint le lieu de débats, mais aussi de création de liens entre les femmes qui expérimentaient de nouvelles relations de solidarité et d'aide mutuelle, parfois d'amours homosexuelles.

Parmi les milliers de pages de publication de cette revue au cours de ses six années d'existence, ce sont les temps de polémiques et quelques unes des œuvres littéraires de sensibilité féministe qui ont forgé son image. Quelques moments essentiels de ces débats sont abordés dans les articles proposés dans ce numéro d'Ebisu : débats autour de la Maison de poupée d'Ibsen (janvier 1912), réponses aux attaques contre la «femme nouvelle» (janvier et février 1913), textes littéraires liés aux débats sur la sexualité, l'amour libre, la chasteté (avril 1912-décembre 1914). D’autres débats, tout aussi essentiels (avortement, prostitution, 1915-1916), qui n'ont pu figurer dans ce dossier, seront présentés dans un ouvrage collectif consacré à la revue.

Seitō bénéficia, lors de son lancement, d'une forme de bienveillance de la part des intellectuels éclairés. La presse manifestait un mélange de curiosité et de méfiance. La revue élargit très vite son audience à travers tout le pays auprès des jeunes femmes avides de changement, dépassant ainsi le cercle de celles ayant eu le privilège d'accéder à l'enseignement supérieur ${ }^{4}$. Cent soixante femmes, au moins, ont contribué aux différents numéros de la revue (Raichō kenkyūkai 2001).

\section{La première revue littéraire féministe}

La revue dénonçait, dans certains articles, l'oppression des institutions patriarcales comme le mariage, la morale et les mœurs traditionnels ; ses membres y exprimèrent leur aspiration à la liberté et à l'émancipation, et participèrent concrètement à l'élaboration de nouvelles valeurs autour de la question du mariage, de l'amour et de la sexualité (voir les articles d'Ōta Tomomi et d'Isabelle Konuma). L'illustration pour la couverture du

3. À l'exception de deux numéros manquants en septembre 1914 et en août 1915.

4. Le statut d'université proprement dit ne sera accordé aux écoles d'enseignement supérieur pour filles qu'après les réformes au lendemain de la défaite de 1945. 


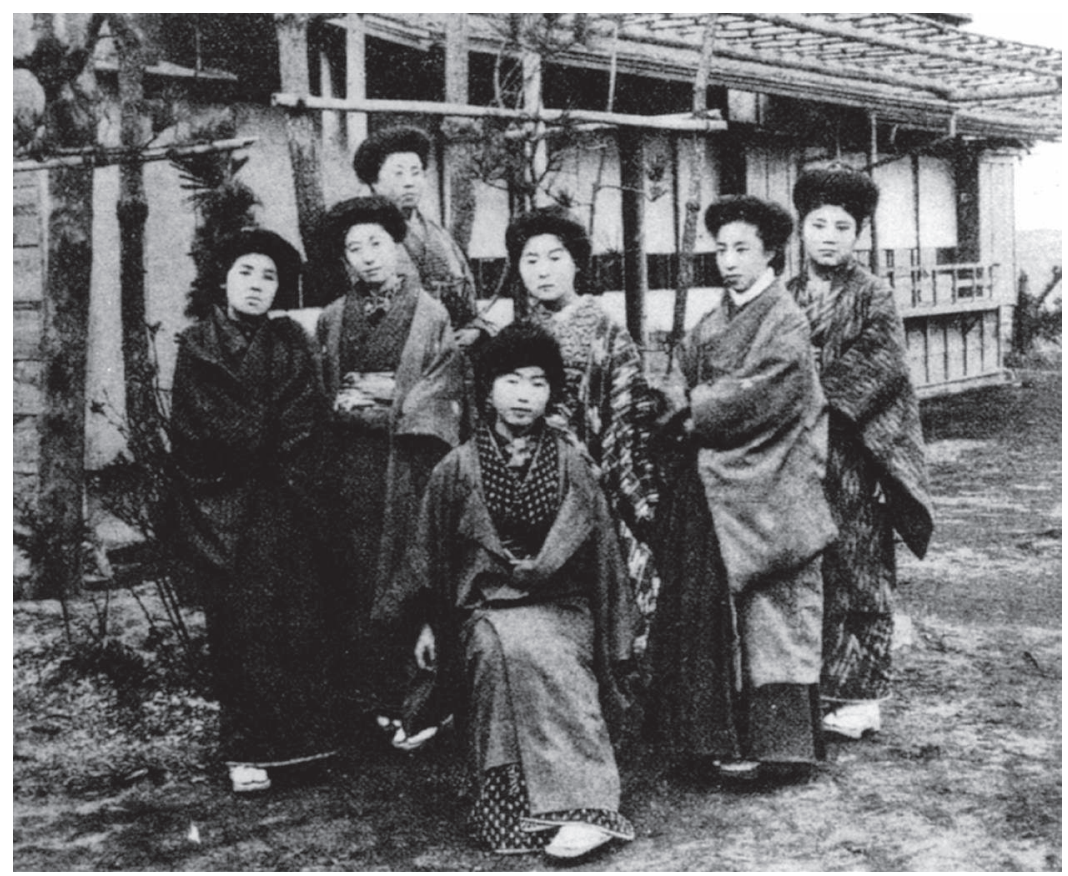

Fig. 1. Photo de membres de la Seitōsha, prise lors du nouvel an fêté à Ōmori Morigasaki Fujikawa 大森森ヶ崎富士川. Publié dans Seitō en février 1912 (p. 100), reprise par la revue Taiyō 太陽 dans son numéro spécial sur la question féminine avec la légende : « Iwayuru atarashii mondai no onna » 所謂新しい問題の女 (Les femmes nouvelles en question). Au centre, assise, Naganuma Chieko, dessinatrice de la couverture du premier numéro de Seitō.

premier numéro, dessinée par Naganuma Chieko 長沼智恵子 (1886-1938) ${ }^{5}$ à la demande de Hiratsuka Raichō 平塚らいてう (1886-1971), nous montre une femme habillée à la grecque ${ }^{6}$ dans un style épuré et Art nouveau, le

5. Future épouse du célèbre sculpteur Takamura Kōtarō 高村光太郎 (1883-1956), elle finit ses jours en hôpital psychiatrique où elle a réalisé au moyen de découpages de papier une œuvre originale exposée dans le musée qui lui est consacré dans sa ville natale à Nihonmatsu 二本松 (département de Fukushima).

6. Hasegawa Nyozekan 長谷川如是閑 (1875-1969), alors correspondant à Londres, avait donné dans un article consacré à la manifestation des suffragettes une description 
menton légèrement tourné vers le haut dans une posture remplie d'espérances (Hiratsuka 1992, vol. 1 : 354). Mais lorsque l'on observe l'image de près, elle est entourée de motifs de kimono, certaines analystes y ont lu le symbole des mœurs qui lient la femme japonaise et dont celle-ci aspire à se déprendre.

Seitō fut-elle plutôt littéraire ou plutôt féministe ? La revue a, sans conteste, regroupé des femmes qui ont joué un rôle essentiel dans le mouvement féministe par la suite, sur le plan social, politique ou littéraire au Japon. Elle a ouvert une porte vers l'émancipation symbolique des femmes, assignant au domaine littéraire un rôle libérateur. Dès le premier numéro, le ton est féministe : le poème de Yosano Akiko 与謝野晶子 (1878-1942), Sozorogoto そぞろごと (Flânerie), particulièrement son premier vers «Yama no ugoku hi kitaru»山の動く日来る (Le jour où la montagne gronde est arrivé), est devenu l'emblème de l'émancipation des femmes ${ }^{7}$. Quant à Raichō ${ }^{8}$, c'est un cri de révolte et d'espérance qu'elle signe avec " À l'origine, la femme était le soleil " ("Genshi, josei wa taiyō de atta " 元始、 女性は太陽であった, infra «Manifeste») et qui, aujourd'hui encore, reste le symbole du féminisme au Japon. La nouvelle de Tamura Toshiko 田村俊子 (1884-1945) dans ce premier numéro, Ikichi 生血. (Sang vivant), annonce également les débats futurs de la revue autour de la virginité et de la chasteté (voir l'article d'Isabelle Konuma).

L'attirance qu'exerça la revue sur ses contemporaines doit certes beaucoup à la personnalité et à la volonté de Hiratsuka Raichō, à son image

détaillée du défilé qui comprenait des femmes habillées en tunique grecque (Tokyo Asahi shinbun 東京朝日新聞, 1-3 août 1910). Serait-ce une source d'inspiration?

7. Sur Yosano Akiko, voir l'ouvrage de Claire Dodane (2000).

8. Son prénom de naissance est Haru, Raichō est son prénom de plume qu'elle adopte à partir de la publication de Seitō. À l'époque Meiji, les prénoms féminins se terminaient beaucoup moins systématiquement par «ko" 子 que de nos jours. Dans la revue Seitō les auteures signent de leur prénom avec le suffixe " ko " dans le premier numéro mais sans par la suite. Cette particule était d'usage récent pour les prénoms féminins et semblait avoir un caractère honorifique, mais soulignait surtout leur féminité. C'est donc aussi un refus d'une forme de féminité qui s'affirme par ces signatures. Il est à noter que beaucoup de prénoms sonnent masculin selon les critères actuels. Selon Horiba (1988: 76-78), c'est à partir de 1908 que l'usage d'accoler « ko » se répand. 


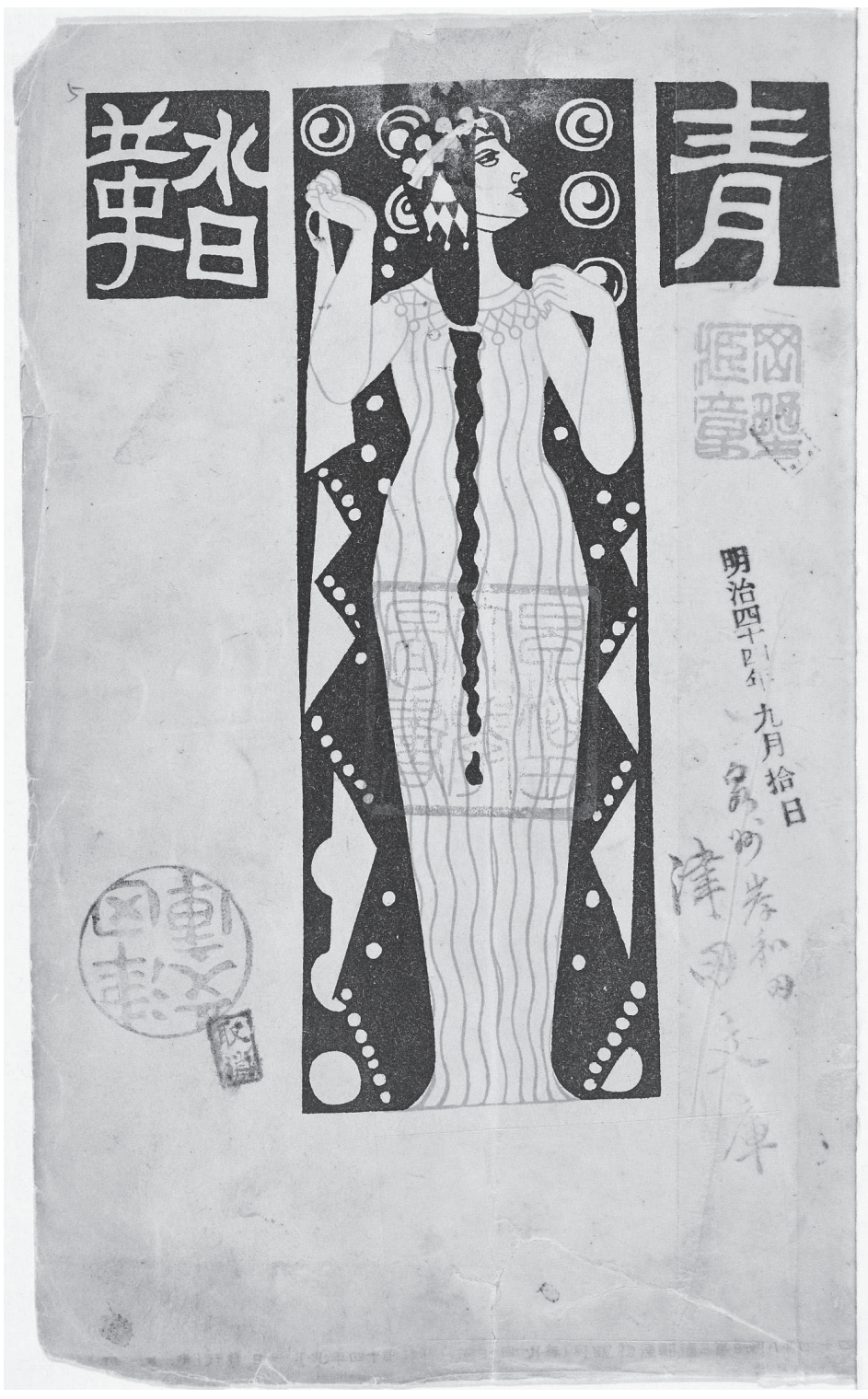

Fig. 2. Couverture du premier numéro de Seitō, septembre 1911, avec un dessin de Naganuma Chieko. Bibliothèque de l'université Waseda. 
déjà médiatisée ${ }^{9}$. Elle garda le leadership jusqu'en 1915, avant de céder la direction de la rédaction à Itō Noe 伊藤野枝 $(1895-1923)^{10}$, de dix ans sa cadette. Raichō avait été étiquetée comme une "femme nouvelle " dès 1910, lorsque le terme d'atarashii onna 新しい女 fit son apparition - avant même la parution de Seitō - dans la presse et dans les conférences (voir les articles de Christine Lévy et de Marion Saucier).

Souvent, la discontinuité entre les pionnières du féminisme du début de l'ère Meiji et les membres de Seitō fut soulignée. Il est vrai qu'à la place des revendications politiques ce sont plutôt la créativité, la liberté et le développement des talents littéraires féminins qui furent mis en avant. Mais ne seraient-elles pas redevables aux premières féministes plus qu'elles n'en ont conscience au moment où elles publient leurs textes, comme le suggère Vera Mackie (2003) ? Lors du « Mouvement pour la liberté et les droits démocratiques ", durant la décennie 1874-1884, les noms de Kishida Toshiko 岸田俊子 (1863-1901) et de Kusunose Kita 楠瀬喜多 (1836-1920) sont restés célèbres (Mackie 2003). La répression eut raison de leur mobilisation et les lois promulguées dès 1890 puis en 1900 interdirent aux femmes toute activité politique ${ }^{11}$. Il fallut attendre les années 1900 pour voir d'autres femmes à leur suite s'engager dans un mouvement politique. Fukuda Hideko 福田英子 (1865-1927), devenue féministe après avoir assisté à un discours de Kishida, lança en 1907 une revue féministe et socialiste Sekai

9. Raichō avait été exclue de l'Ōfūkai 桜楓会, l'association des anciennes étudiantes de l'Écoled'enseignementsupérieur pourjeunesfilles, la Nihon joshi daigakkō日本女子大学校 fondée en 1901, à la suite d'une affaire de tentative de double suicide avec Morita Sōhei 森田草平 (1881-1949) qui fit scandale dans la presse en 1908, connue sous le nom de Shiobara jiken 塩原事件 (l'affaire Shiobara).

10. Elle devint anarchiste, puis vécut avec son amant Ōsugi Sakae 大杉栄 (1885-1923). Ils furent assassinés avec leur neveu, Tachibana Sōichi 橘宗一, lors du tremblement de terre de 1923 (Amakasu jiken 甘粕事件 l'affaire Amakasu). Voir aussi note 14.

11. La loi de 1890, Shükai oyobi seisha hō 集会及び政社法 (Loi sur les rassemblements et organisations politiques), interdit aux femmes toute participation à une quelconque réunion politique, à toute organisation politique et si elles se réunissaient à plus de trois, elles devaient en avertir la police. Elles étaient exclues du droit de vote et de toute éligibilité. La loi de police sur l'ordre public promulguée en 1900 (Chian keisatsu hō 治安警察法) reprit tels quels les interdits dans son article 5 et fut combattue par les militantes socialistes. Ce combat fut repris par les féministes issues de l'association Seitōsha, avec la Shinfujin kyōkai 新婦人協会 (Association de la femme nouvelle), association créée en 1920. 


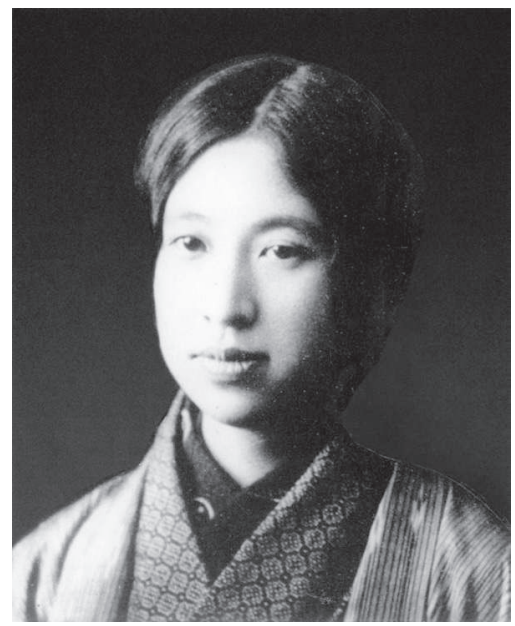

Fig. 3. Portrait de Hiratsuka Raichō en 1911

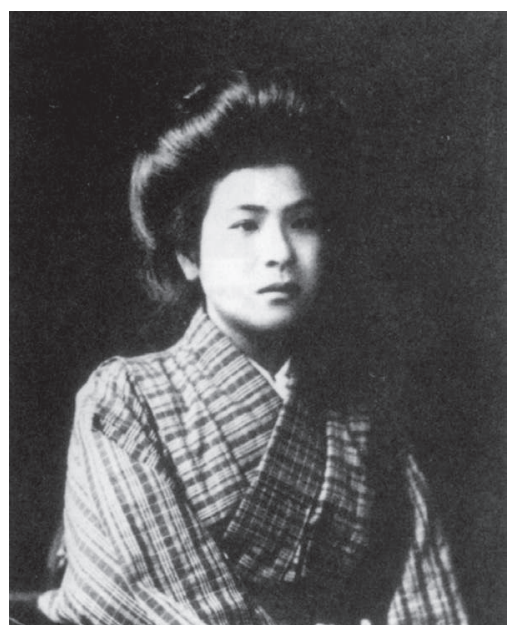

Fig. 4. Portrait d'Itō Noe vers 1913

fujin 世界婦人 (Femmes du Monde) ${ }^{12}$. Entre 1904 et 1909, des militantes socialistes lancèrent des pétitions pour réclamer la révision de la loi de 1900. Leur mobilisation, certes, fut modeste en regard de l'activisme des suffragettes en Europe, mais elles tracèrent des perspectives qui allaient être reprises après la Première Guerre mondiale, lorsque la répression contre le mouvement socialiste - qui envoya ses principaux dirigeants à l'échafaud en 1911 - fit place à une politique plus libérale pour une décennie.

Entre ces deux périodes, celle de l'effervescence du premier mouvement socialiste (1900-1907) et celle de la libéralisation politique au lendemain de la Première Guerre mondiale, la revue Seitō occupa une place spécifique, tournée vers la littérature plus que vers des buts politiques. C'était en partie un compromis face au contexte de répression et de censure (voir l'article d'Odaira Maiko), où la moindre tentative d'expression idéologique ou politique était réprimée. Par exemple, un article écrit par la socialiste Fukuda Hideko dans le numéro de février 1913 entraîna son interdiction.

12. Sa publication s'arrête en août 1909, sous les coups de la censure et de la répression. 
Mais les attaques contre la revue se firent tout aussi, sinon plus virulentes au sujet des questions de mœurs et de morale : les foudres de la censure frappent pour la première fois le numéro qui contient la nouvelle d'Araki Iku 荒木郁 (1890-1943), Tegami 手紙 La Lettre (avril 1912), qui traite de l'adultère, puis le numéro avec la nouvelle de Harada Satsuki 原田 泉月 (1887-1933), Gokuchū no onna yori otoko e 獄中の女より男へ D'une femme en prison à son homme (juin 1915), dans laquelle la jeune femme revendique et argumente pied à pied son droit à l'avortement (voir l'article d'Ōta Tomomi) ${ }^{13}$. Des jets de pierres au domicile de Hiratsuka Raichō, des lettres de menace de mort envoyées au bureau de la rédaction de Seitō disent clairement l'atmosphère d'hostilité à leur égard. Bientôt les flèches acerbes contre les «femmes nouvelles " pleuvront de toutes parts. Kamichika Ichi 神近市 (1888-1981) ${ }^{14}$ perdit son poste d'institutrice dans le département d'Aomori pour avoir appartenu à Seitō, malgré le recours à un pseudonyme (Horiba 1991 : 125).

Les débats menés entre les membres de Seitō reflètent néanmoins les transformations de la condition féminine de l'époque Meiji : critiquer la conception de la "bonne épouse, mère avisée » (ryōsai kenbo 良妻賢母) ${ }^{15}$ exigeait au préalable l'acquisition d'un outillage théorique et conceptuel. Celui-ci permettait d'argumenter le refus de ce destin dans un langage rationnel tout en valorisant l'expression de ses propres désirs.

L'accès à l'enseignement supérieur fut déterminant dans le processus de création de Seitō : sur les cinq membres fondatrices de la revue Seitō, quatre étaient d'anciennes étudiantes de l'École d'enseignement supérieur pour jeunes filles (Nihon joshi daigakkō 日本女子大学校) et, par la suite, au moins une trentaine d'anciennes étudiantes de cet établissement contribuèrent à la revue (Horiba 1988 : 10). Les étudiantes, à cette époque, furent l'objet de

13. Ces deux nouvelles seront publiées dans un ouvrage collectif sur Seitō, comme les autres articles cités dans cette introduction.

14. Elle est célèbre pour avoir tenté d'assassiner Ōsugi Sakae par jalousie lorsque celui-ci eut une relation amoureuse avec Itō Noe. (Cette affaire connue sous le nom de Hikagejaya jiken 日蔭茶屋事件 est reprise dans le film Eros + massacre réalisé en 1969 par Yoshida Kijū [Yoshishige] 吉田喜重). Pour son prénom, on trouve Ichi ou Ichiko, voir note 8 .

15. Voir notre article sur le débat autour d'Une Maison de poupée, notamment note 15 et autres. 
nombreux sarcasmes ou de critiques : même Yosano Akiko leur reprochait l'usage des pronoms masculins boku et kimi, ce qui, aujourd'hui encore, ne se fait pas (ibid. : 22). Leur tenue vestimentaire, leur manque de modestie sont pointés comme des signes de décadence. Leur ambition est considérée comme une menace pour une vie familiale bien ordonnée. Dès 1909, une campagne de dénigrement de l'éducation supérieure pour les filles, sous prétexte qu'elle ne servirait qu’à implanter des idées libérales dans leurs « cerveaux ", avait poussé des femmes reconnues dans le monde académique, comme Tsuda Umeko 津田梅子 (1864-1929), Miwata Masako 三輪田 真佐子 (1843-1927), Tanahashi Ayako 棚橋綾子 (1839-1939), à prôner un retour aux valeurs confucianistes dans l'enseignement assuré aux filles. Elles avaient rédigé un texte, en 1909, sous le titre Shin Onna daigaku an 新女 大学案 (Une proposition pour une nouvelle Onna daigaku [La Grande Étude des femmes $]^{16}$ ), indiquant clairement leur volonté de revenir aux valeurs confucéennes de soumission de la femme, fussent-elles « renouvelées ».

Cependant, sur le plan professionnel le débouché de ces écoles supérieures ne dépasse pas le niveau d'institutrices ou d'enseignantes du secondaire, et les fonctions de cadre ou autres métiers très qualifiés leur sont totalement fermés. On comprend mieux pourquoi, dans ces conditions, les aspirations des membres de Seitō se concentrèrent sur l'idée d'une carrière littéraire, la seule qui leur était ouverte. Celles qui avaient commencé à publier furent nombreuses à soutenir et à participer à l'aventure de Seitō. Par exemple, sur les dix auteures dont la revue Chūō köron 中央公論 publia des nouvelles en décembre 1910, neuf participeront d'une manière ou d'une autre à l'entreprise ${ }^{17}$ (Horiba 1988 : 52-53).

16. Onna daigaku est tiré d'un texte de Kaibara Ekiken 貝原益軒 (1630-1714) qui légitimait la soumission de la femme à son mari et aux hommes de sa famille par sa supposée passivité. Parmi la prescription des normes de comportements, on y trouve les célèbres sept motifs de répudiations (shichikyo 七去) codifiés par les textes: 1) manque de docilité envers les beaux-parents ; 2) absence de progéniture ; 3) bavardage ; 4) vol ; 5) débauche ; 6) jalousie ; 7) maladie pernicieuse. Voir la traduction de Claire Dodane (2008: 157-166).

17. Nagayo Michiyo 永代美知代 (1885-1968), connue pour avoir servi de modèle pour la jeune Yoshiko du roman Futon de Tayama Katai 田山花袋 (1871-1930), est la seule à ne pas avoir participé, simplement parce qu'ayant déménagé à Toyama, elle ne prit pas connaissance de l'invitation de Seitō. 
L'histoire de cette revue nous permet de saisir un des aspects majeurs du bouleversement que la société japonaise a connu au cours de l'ère Meiji. Pas plus qu'en Occident, les fondements d'une domination masculine ne furent remis en cause. Cependant, ses modalités furent transformées avec la modernisation et l'occidentalisation. Même si les réactions traditionalistes ou culturalistes, ainsi que la volonté politique de maintenir l'ordre social à travers le respect de l'ordre familial patriarcal, n'ont pas manqué de contrer des revendications ou des manifestations jugées trop féministes, certains changements importants ont fait progresser la condition féminine. La socialisation des filles et des jeunes femmes à travers la scolarisation, l'affirmation du nouveau rôle de la femme dans la famille, comme épouse légitime et éducatrice des futures générations, ont conduit les femmes à jouer un rôle majeur dans l'interface entre la tradition et la modernité. Devant à la fois se conformer au conservatisme et s'adapter à la modernisation, certaines voulurent dépasser cette contradiction en se débarrassant de l'aliénation personnelle. Ce rejet de l'aliénation rejoint directement les thématiques des mouvements qui sont nés dans les années 1960 et leur donne probablement ce ton si actuel.

\section{Les études sur Seitō : historique et perspectives}

\section{Les études d'avant-guerre jusqu'à la défaite de 1945}

La première analyse systématique fut publiée sous la plume polémique de Yamakawa Kikue (infra Kikue) 山川菊栄 (1890-1980), en 1921 : elle expliquait l'historique du mouvement féministe dans un article publié en juillet dans la revue Taiyō 太陽. Son bilan était très critique, qualifiant la revue Seitō de bourgeoise et d'individualiste, d'utopiste pour ne reprendre que les termes les moins durs. Kikue, dans cet article, défendait les positions de l'organisation socialiste des femmes qu'elle avait fondée avec d'autres militantes, Sekirankai 赤瀾会 (L'association de la vague rouge), en s'attaquant au mouvement que Hiratsuka Raichō avait créé en 1919, Shinfujin kyōkai, pourtant la plus progressiste des organisations de femmes de son époque. Mais en 1962, la même auteure écrira que la revue Seitō avait joué un rôle fondamental dans la démystification de la famille, en s'attaquant à la question taboue et sacralisée de la morale sexuelle. Elle estimait que Seitō 
avait permis aux femmes de penser par elles-mêmes, de se donner courage et confiance ${ }^{18}$.

Citons également une étude littéraire pionnière sur Seitō publiée en février 1924 par Katō Asatori 加藤朝鳥 (1886-1938) ${ }^{19}$ dont les conclusions étaient que la revue littéraire avait adopté une perspective féministe. Pour lui, c'est le débat sur les pièces de théâtre modernes, à commencer par celles d'Ibsen, qui inaugura cette perspective idéologique. Il accorde une valeur intrinsèque à la création par les femmes elles-mêmes d'une revue littéraire. Ses appréciations sont favorables, à l'opposé d'un écrivain, Kataoka Teppei 片岡鉄兵, qui, en juillet 1926, tout en reconnaissant une grande valeur à Seitō, reprendra dans son article les calomnies qui avaient déferlé dans la presse après l'affaire dite du " cocktail aux cinq couleurs " (goshiki no sake 五色の酒 $)^{20}$ et celle suscitée par la visite de certaines des membres de Seitō au quartier de prostitution de Yoshiwara, espace interdit aux femmes. Surtout, il leur déniait toute nouveauté authentique, leur reprochant d'imiter les hommes dans la vie quotidienne plutôt que de créer une nouvelle vie à partir de leur point de vue. Ikuta Hanayo 生田花世 (1888-1970) ${ }^{21}$ ne manqua pas de lui répondre dans la même revue le mois suivant, le renvoyant à l'irresponsabilité des journalistes qui participèrent à la campagne de dénigrement des membres de Seitō, en occultant leur volonté et leurs efforts pour s'élever dans tous les domaines culturels. Pendant la décennie 1927-1937, Raichō est la seule à proposer des analyses sur la place historique de la revue. En juin 1927, elle publie un article dans la revue Taiyō ("Seitōsha no koto »

18. On peut penser que le positionnement de Raichō, " compagnon de route " du Parti communiste japonais après la guerre, notamment de part son rôle au sein du Mouvement des mères (Hahaoya undō 母親運動) lancé contre les essais de la bombe $\mathrm{H}$ en 1954, n'est pas pour rien dans cette appréciation positive (voir infra, note 29).

19. Celui-ci fut l'amant de Katō Midori avec qui il vécut en union libre, puis qu'il épousa officiellement.

20. La presse produisit des caricatures sur ces femmes buvant ces cocktails à la mode à l'époque, dans des bars qu'elles n'auraient pas dû fréquenter (Mackie 2003 : 47). On verse dans un verre, par ordre de densité, crème de cassis, menthe, marasquin, vanille et cognac, ce qui permet d'obtenir un verre aux cinq couleurs rayées rouge, bleu, blanc, vert, châtaigne. Otake Kōkichi (Beniyoshi) 尾竹紅吉 avait l'habitude de tout rapporter avec exagération et raconta partout qu'elle avait bu cul sec ce verre de cocktail aux cinq couleurs qui brillait comme un arc-en-ciel.

21. Sur cette auteure, voir l'article d'Ōta Tomomi dans ce même dossier. 
青鞜社のこと [À propos de l'association Seitōsha]) dans lequel elle souligne combien la revue avait représenté une tentative essentielle pour échapper à la seule perspective qui était offerte alors aux femmes, au cadre étriqué de la "bonne épouse, mère avisée ", tout en reconnaissant certaines faiblesses, comme l'insuffisance de sa conscience sociale et politique, et critiquant la revue pour son enfermement dans l'individualisme libéral. Elle rappelle que toutefois les attaques incessantes et violentes contre la revue les obligèrent à prendre conscience de la question sociale, au moins partiellement (Hiratsuka 1983, vol. 4 : 298-304). Elle compare Seitō à un kimono dont elle s'est défaite sans regret au cours de sa croissance. En 1937, elle publia une série de six articles entre janvier et juillet, pour présenter de façon très concrète les activités de quelques unes de ses membres (Hiratsuka 1983 vol. 6 : 168-210).

En 1939, puis en 1947, Miyamoto Yuriko 宮本百合子 (1899-1951), célèbre auteure, membre du Parti communiste, considéra que Seitō devait sa naissance à l'affaire Shiobara ${ }^{22}$, parce que face à Morita Sōhei qui relatait l'affaire dans son roman Baien 煤煙 (Suie), Hiratsuka Raichō n’avait pas eu les moyens d'en écrire un en réponse. Miyamoto affirme que celle-ci trouva pour faire entendre sa voix cette perspective collective (Miyamoto 1973). Elle considère également que le texte inaugural de Raichō, "À l'origine, la femme était le soleil ", est un texte entièrement mystique, reprenant en cela l'appréciation d'Ōsugi Sakae, le compagnon ultérieur d'Itō Noe. Elle reconnaît néanmoins une grande valeur littéraire à Seitō dans son ensemble.

\section{Les décennies 1950 et 1960}

En 1952, une polémique opposa l'appréciation plutôt négative d'Itagaki Naoko 板垣直子 (1896-1977) sur la portée historique de Seitō du point de vue littéraire ${ }^{23}$, à celle d'Okano Takeo 岡野他家夫 (1901-1989) qui considérait au contraire que la revue avait permis que s'y forgent des personna-

22. Sur cette affaire, voir note 9 de cette introduction et note 41 de l'article sur le débat autour d'Une Maison de poupée dans ce même dossier.

23. Cet article est repris dans son ouvrage publié en 1967 (réédition par la suite). Notons que la maison d'édition est celle de l'association des anciennes étudiantes de l'école Nihon joshi daigakkō, où Raichō ne fut réhabilitée qu'en 1992. 
lités prestigieuses sur le plan culturel. Pour Okano, les difficultés d'accès à l'ensemble des numéros, la place minime accordée à l'étude des auteures, expliquent ce mépris. Mais après 1955, la place de Hiratsuka Raichō dans le mouvement pacifiste et son action contre les essais nucléaires américains de Bikini ${ }^{24}$ permet un rappel à tous de l'existence de Seitō. Elle raconte dans sa première autobiographie (Hiratsuka 1955) le processus de la création de Seitōsha et ses souvenirs sur ses membres. Son succès n'est pas négligeable puisqu'en juillet 1955, les tenugui (essuie-main qui reproduisent des motifs de dessins japonais) avec une calligraphie de Raichō ${ }^{25}$, édités lors du premier congrès du Mouvement des mères, sont vendus à 130000 exemplaires (Sasaki 1994 : 119). L'année suivante, en juin 1956, Kusabe Kazuko 草部 和子 proposait une analyse détaillée du contenu de tous les numéros, dans le périodique Bungaku 文学 (Littérature). Selon elle, les auteures Araki Iku, Kiuchi Tei 木内錠 ${ }^{26}$, Sugimoto Masao 杉本正生, Katō Midori se sont révélées grâce à leur passage à Seitō.

Le premier ouvrage systématique parut pour le cinquantenaire en 1961. Ce fut l'ouvrage d'Ide Fumiko 井手文子 (1920-1999), qui reprenait le titre du Manifeste de Raichō, Seitō. Genshi, josei wa taiyō de atta『青鞮』 一元始、女性は太陽であった (Seitō. À l'origine, la femme était le soleil) (Ide 1961). Ide Fumiko qui avait vécu sa jeunesse entre la sombre période de la guerre et l'atmosphère de libération de l'après-guerre, fut stupéfaite de découvrir dans un passé qu'elle n'avait pas connu une revue comme Seitō qui représentait précisément ce qu'elle recherchait : l'établissement d'un moi autonome moderne et la conscience de la solidarité sociale. Pour elle, la clé de la lecture de Seitō est l'autonomie du sujet féminin. Son ouvrage critiqué pour certains de ses défauts - le manque de précision historique - fut réécrit en 1975, sous le titre Seitō no onnatachi『青鞜』の 女たち (Les femmes de Seitō). Elle rédigea également un ouvrage sur Itō

24. Hiratsuka Raichō devint en septembre 1954 vice-présidente de la Kokusai minshu fujin renmei 国際民主婦人連盟 (Women’s International Democratic Federation) créée en 1945 (Yoneda 2012 : 57).

25. Sekaijū no okāsan te o tsunagimashō 世界中のお母さん手をつなぎましょう (Mères du monde entier, donnons-nous la main) : http://hahaoyataikai.jp/02_taikai/taikai_1/ taikai_1.html (consulté le 12 août 2012).

26. Pour ces deux prénoms, on trouve également Ikuko et Teiko, voir note 8. 
Noe (1979), ainsi qu'un autre ouvrage sur la modernité et le mysticisme de Raichō (1987).

En 1961, un autre article traçait également des perspectives d'étude sur Seitō. Son auteure, Koyasu Michiko 子安美知子, soulignait la rupture que représentait la revue avec ce qui avait été alors consacré comme « littérature féminine " depuis Higuchi Ichiyō 樋口一葉 (1872-1896) et Yosano Akiko. Elle insistait sur l'influence nietzschéenne et celle d'Ibsen, qui avaient permis cette démarcation.

\section{De la redécouverte aux études systématiques}

Les recherches sur Seitō ont connu un bond sur le plan académique grâce d'abord à la publication en fac-similé de la collection complète des numéros, en 1969 chez l'éditeur Meiji bunken 明治文献, puis en 1980 chez Ryūkei shosha 龍溪書舎. En 1983, Fuji shuppan 不二出版 proposait une nouvelle édition complète. Ces éditions prouvent l'intérêt renaissant pour une revue qui était tombée dans l'oubli. Deux moments distincts expliquent ce regain d'intérêt : d'une part le mouvement féministe des années 1970, et d'autre part les évolutions juridiques importantes du statut de la femme à partir de la décennie 1980 .

La publication des œuvres des deux dirigeantes, Hiratsuka Raichō et Itō Noe, ainsi que de leurs biographies, ont joué un rôle important dans ce regain d'attention. La redécouverte dans les années 1960-1970 des premières féministes se cristallise autour des textes de Seitō, qui surprennent par leur modernité, l'actualité de leurs préoccupations. La référence que fait un groupe né dans les années 1970, Onna erosu 女・エロス (Femmes/ Éros, 1973-1983), au "Manifeste " de Seitō ${ }^{27}$, le sous-titre d'une revue féministe, Feminisuto フェミニスト, publiée par Atsumi Ikuko 渥美郁子 en 1977-1978, Atarashii onna tachi no Seitō 新しい女たちの『青鞜』(Le Seitō des femmes nouvelles ${ }^{28}$, traduisent le désir d'intégrer un héritage féministe, confirmant l'analyse de Joan Scott (2010) à propos de l'histoire du féminisme en général.

27. Il s'agit du texte de Hiratsuka Raichō, "À l'origine, la femme était le soleil " (traduction à paraître).

28. Le premier numéro était sous-titré Atarashii Seitō 新しい『青鞜』(Un nouveau Seitō). 
Dans les années 1970, de nombreux ouvrages virent le jour, notamment à propos des membres moins connues. L'émergence de groupes d'étude dans les provinces révèle des participantes ou des lectrices de la revue jusque-là inconnues. Tous ces travaux permettent la publication d'ouvrages de synthèse comme celui de Horiba Kiyoko 堀場清子 sur l'époque de Hiratsuka Raichō et sur les femmes nouvelles (Horiba 1988).

La décennie 1980 commence avec la signature par le Japon, en 1981, de la Convention sur l'élimination de toutes les formes de discrimination à l'égard des femmes ${ }^{29}$, entrée en vigueur en $1985^{30}$. Cette signature entraîna, entre autres, un changement de la législation sur la nationalité (transmissible désormais par la mère et non plus uniquement par le père) et sur l'emploi, avec l'adoption de la Loi sur l'égalité des chances entre hommes et femmes dans le domaine de l'emploi (Danjo koyō kikai kintō hō 男女雇 用機会均等法), entrée en vigueur en $1986^{31}$. C'est dans la seconde moitié des années 1980 que les études sur Seitō précisément se multiplièrent. Les chercheures retrouvent un écho de leur propre vécu à la lecture de ces textes (Iwata 2003 : 230). Elles s'interrogèrent sur la possibilité de faire revivre ce qui, après quatre-vingts ans de silence, les faisait vibrer encore et se révélait à elles avec tant de fraîcheur. Cette quête les mena à découvrir aussi les premières analyses.

\section{Le temps de la critique et du renouvellement}

La décennie 1990 connaîtra des études plus spécifiques sur l'aspect littéraire, à côté de celles sur l'histoire des femmes et du genre. Iwata Nanatsu 岩田ななつ (1993, 2003) publie divers titres, et le groupe d'étude Shin feminizumu hihyō no kai 新・フェミニズム批評の会32 (1998) propose une étude assez systématique (voir l'article d'Odaira Maiko). Une étude des genres littéraires autres que le roman vit enfin le jour. Du point de vue de l'histoire des femmes et du genre, la grande spécialiste de Hiratsuka Raichō,

29. Voir le texte : http://www.un.org/womenwatch/daw/cedaw/text/fconvention.htm (consulté le 10 août 2012).

30. Voir : http://www.jicl.jp/now/jiji/backnumber/1986.html (consulté le 10 août 2012). 31. Voir : http://femmesgenreetlasocietejaponaise.blogspot.jp/2012/01/i-les-femmeset-lemploi-au-japon-de.html (consulté le 10 août 2012).

32. Association pour une nouvelle critique féministe. 
Yoneda Sayoko 米田佐代子, analyse les rapports entre le genre et la démocratie à l'époque Taishō (1912-1926) à travers l'étude de Raichō et les activités de Seitō (2002). Parmi de nombreux ouvrages on notera la réalisation du dictionnaire biographique de 110 des participantes (Raichō kenkyūkai 2001) qui constitue un outil précieux. Les titres sont trop nombreux pour que nous les citions tous ici. Les études sont également plus individualisées. Nous renvoyons le lecteur aux différentes bibliographies présentées dans les articles qui suivent.

Parallèlement à ces études, il faut noter cependant le développement d'un regard critique et une certaine désaffection vis-à-vis de Hiratsuka Raichō notamment par rapport à une période pour laquelle on peut parler d'un « boom Raichō", celle qui suivit la publication de son autobiographie en 1971-1973, bien que celle-ci demeure encore aujourd'hui parmi l'une des meilleures ventes dans le genre ${ }^{33}$. Ses œuvres complètes en huit volumes (1983-1984) furent vendues à trente mille exemplaires. Setouchi Jakuchō 瀬戸内寂聴 en publiant le roman Seitō en deux volumes en 1984 contribua également à populariser ce mouvement féministe d'avant-guerre et la figure de Hiratsuka. En 1989, Hino Takako 日野多香子 rédigea même un livre pour enfant intitulé « Hiratsuka Raichō. Pionnière d'une époque de rayonnement pour les femmes » (Hino 1989). En 1996, un manga qui retrace sa vie fut dessiné par Takeuchi Ranko 竹中らんこ.

Enfin, les années 1990 connaissent une rupture essentielle, tant dans les méthodologies, les problématiques que sur le plan idéologique, le nationalisme devenant une cible privilégiée de la critique académique. L'introduction du concept de genre, la nécessité d'un féminisme transnational, la critique de la participation politique à la mobilisation de guerre de la part de certaines dirigeantes du féminisme d'avant-guerre, notamment de Takamure Itsue 高群逸枝 (1894-1964) et d'Ichikawa Fusae 市川房枝 (1893-1981), l'irruption des questions liées au post-colonialisme avec la question de l'esclavage sexuel des «femmes de réconfort» (ianfu 慰安婦), remettent en cause les courants féministes d'avant-guerre.

Seitō n'est pas directement visée par ces critiques, puisque son existence se limite à la première période de Taishō. Les critiques concernent

33. Plus de deux cent mille exemplaires vendus entre 1971 et 1991 d'après son éditeur, et son édition de poche, parue en 1992, continue à connaître une bonne diffusion. 
ses limites comme son idéalisation du couple hétérosexuel : s'appuyant sur les paradigmes proposés par Judith Butler selon qui la généalogie du sujet politique du féminisme repose sur la définition d'une « féminité » conforme à l'ordre hétérosexuel, certaines féministes japonaises considèrent que les membres de Seitō ne sont pas sorties du cadre de la morale sexuelle définie par l'État pour exercer son contrôle (Ōkoshi 2005 : 54-55). Nous avons vu pourtant que c'est dans ce domaine - celui de la morale sexuelle - que les réactions de tous les milieux furent les plus virulentes. Il y a un certain anachronisme à juger selon les normes actuelles - parfois théoriques - les comportements et leurs critiques liés à un autre temps. Leurs revendications féministes à l'époque provoquèrent de vives réactions de la part de la majorité des hommes, y compris chez les intellectuels. De façon contrastée, en apparence du moins, en Chine, les intellectuels modernisateurs ou révolutionnaires reprochèrent aux femmes chinoises leur manque de volonté émancipatrice (voir l'article de Niimura Yōko). Un enjeu commun pourtant s'en dégage, celui de confiner les femmes à une place précise, dans la famille et dans la société, à l'écart du pouvoir et des initiatives, tout en leur demandant de suivre les hommes dans leur œuvre de modernisation.

Parce qu'elles ont fait entendre leurs propres voix et se sont écartées de ce que les hommes attendaient d'elles, les membres de Seitō ont joué un rôle subversif qu'il n'était pas aisé de tenir, reconnu comme tel dans les années 1970. Si de nouvelles approches, comme par exemple celles d'Odaira Maiko (2008), permettent d'interroger le sens même des normes modernes de la féminité, de nouvelles perspectives d'étude se dégagent aussi des derniers travaux qui mettent en relief les liens entre les membres de Seitō et les "femmes nouvelles" d'autres pays non seulement occidentaux, mais aussi asiatiques (Muta 2006). Leurs liens à travers le monde sont mis en valeur par des recherches récentes ("Atarashii onna " kenkyūkai 2011) qui nous permettent de penser ce mouvement dans une perspective plus globale. Le partage du masculin et du féminin a été remis en cause depuis sa parution, et si la notion de performativité de l'identité du genre au sens défini par Judith Butler (1990) est nouvelle, l'idée qu'elle n'est pas donnée est clairement affirmée dans la revue Seitō qui faisait preuve d'une maturité remarquable dans la réflexion sur les différences de sexes.

Christine LÉvy 


\section{Bibliographie}

« Atarashii onna » kenkyūkai

「新しい女」研究会 (éd.) 2011

Seitō to sekai no « atarashii onna » tachi

『青鞜』と世界の「新しい女」たち (Seitō et les « femmes nouvelles » à travers le monde), Tokyo, Kanrin shobō 翰林書房.

\section{BARDSLEY Jan 2007}

The Bluestockings of Japan:

New Woman Essays and Fiction from

Seitō, 1911-16, Center for Japanese

Studies, Ann Arbor, The University

of Michigan.

\section{BUTLER Judith 1990}

Gender Trouble: Feminism and the

Subversion of Identity, New York,

Routledge [2005 pour la traduction

française, Trouble dans le genre.

Pour un féminisme de la subversion,

Paris, La Découverte].

DODANE Claire 2000

Yosano Akiko, poète de la passion

et figure de proue du féminisme japonais,

Paris, POF.

\section{DODANE Claire 2008}

"Le grand savoir des femmes (Onna daigaku)», IRIS, numéro «Imaginaire et poétique de la femme au Japon» édité par Jean-Pierre GIRAUD : 157-166.

\section{FUJIME Yuki 藤目ゆき 1997}

Sei no rekishigaku. Kōshō seido, dataizai taisei kara baishun bōshi hō, yūsei hogo hō taisei e 性の歴史学一一公娼制度・堕胎罪体制から 売春防止法·優生保護法体制へ
(Histoire de la sexualité.

De l'organisation publique de la prostitution et de la criminalisation de l'avortement à l'interdiction de la prostitution et à la mise en place de l'eugénisme), Tokyo, Fuji shuppan 不二出版.

\section{HINO Takako 日野多香子 1989}

Hiratsuka Raichō. Josei ga kagayaku jidai o hiraku 平塚らいてう一一性が輝く 時代を拓く (Hiratsuka Raichō. Pionnière d'une époque de rayonnement pour les femmes), Tokyo, Sōdo bunka 草土文化.

HIRATSUKA Raichō 平塚らいてう 1955

Watashi no aruita michi 私の歩いた道

(Le chemin que j'ai parcouru),

Tokyo, Shin.hyōronsha 新評論社.

HIRATSUKA Raichō [1971-1973] 1992

Genshi, josei wa taiyō de atta 元始、女性は 太陽であった (À l'origine, la femme était le soleil), Tokyo, Ōtsuki shoten 大月書店, coll. Kokumin bunko 国民文庫, 4 vols.

HIRATSUKA Raichō 1983-1984

Hiratsuka Raichō chosakushū

平塚らいてう著作集 (Hiratsuka Raichō. (Fuvres), 8 vols, Tokyo, Ōtsuki shoten 大月書店.

HORIBA Kiyoko 堀場清子 1988

Seitō no jidai. Hiratsuka Raichō to atarashii onna tachi 青鞜の時代 ——平塚らいてうと新しい女たち (L'époque de Seitō. Hiratsuka Raichō et les femmes nouvelles), Tokyo, Iwanami shoten 岩波書店. 
IDE Fumiko 井手文子 1961

Seitō. Genshi josei wa taiyō de atta 『青䩖』——元始、女性は太陽であった (Seitō. À l'origine, la femme était le soleil), Tokyo, Kōbundō 弘文堂.

\section{IDE Fumiko 1975}

Seitō no onnatachi『青鞮』の女たち (Les femmes de Seitō), Tokyo, Kaien shobō 海燕書房.

\section{IDE Fumiko 1979}

Jiyū sore wa watakushi jishin. Hyōden Itō Noe 自由それは私自身一一評伝·伊藤野枝 (La liberté, c'est moi. Biographie d'Itō Noe), Tokyo, Chikuma shobō 筑摩書房.

\section{IDE Fumiko 1987}

Hiratsuka Raichō. Kindai to shinpi 平塚らいてう一一近代と神秘 (Hiratsuka Raichō. Modernité et mystique), Tokyo, Shinchōsha 新潮社.

\section{IKUTA Hanayo 生田花世 1926}

«Seitōsha no tame ni benzu » 青鞜社の ために辯ず (Plaidoyer pour Seitōsha), in Wakakusa 若草, août, 44.

\section{ITAGAKI Naoko 板垣直子 1967}

Meiji, Taishō, Shōwa no joryū bungaku 明治・大正・昭和の女流文学 (La littérature féminine de Meiji, Taishō, Shōwa), Tokyo, Ōfūsha 桜楓社.

\section{IWATA Nanatsu 岩田ななつ 1993}

Seitō no onna : Katō Midori 青靼の女 ——加藤みどり (Une femme de Seitō : Katō Midori), Seikyūsha 青弓社.

\section{IWATA Nanatsu 2003}

Bungaku to shite no Seitō 文学としての
『青鞜』(Seitō en tant que littérature), Tokyo, Fujishuppan 不二出版.

KATAOKA Teppei 片岡鉄兵 1926 «Modan gāru no kenkyū : Seitōsha no fujin to shizen shugi » モダン・ガールの 研究一一青鞜社の婦人と自然主義 (Les études sur la modan gāru [modern girl] : les femmes de Seitō et le naturalisme), Wakakusa 若草, juillet : 46-49.

\section{KATŌ Asatori 加藤朝鳥 1924}

《Ichiyō ikō no joryū bungaku » 一葉以降 の女流文学 (La littérature féminine après Higuchi Ichiyō), in Fujin kōron 婦人公論 février : 18-23.

\section{KOYASU Michiko 子安美知子 1961}

«Seitō no seiritsu : Hiratsuka Raichōo chūshin to shite»『青鞜』の成立 ——平塚らいてうを中心として (La création de Seitō : autour de Hiratsuka Raichō), in Kokugo to kokubungaku 国語と国文学, 38 (10) : 108-116.

KUSABE Kazuko 草部和子 1956 «Seitō » 青鞜 (Seitō), in Bungaku 文学, juin : 115-121.

\section{MACKIE Vera 2003}

Feminism in Modern Japan: Citizenship, Embodiment, and Sexuality, Cambridge/ New York, Cambridge University Press.

MIYAMOTO Yuriko 宮本百合子 1973 «Bungaku ni miru fujinzō » 文学に 見る婦人像 (Le portrait de la femme vu à travers la littérature), Shin Nihon shuppansha 新日本出版社, coll. Shin Nihon sensho 新日本選書. 
MUTA Kazue 牟田和恵 2006

Jendā kazoku o koete ジェンダー家族を

超えて (Dépasser la famille basée sur le

genre), Tokyo, Shin.yōsha 新曜社.

ODAIRA Maiko 小平麻衣子 2008

Onna ga onna o enjiru; bungaku, yokubō, shōhi 女が女を演じる—文学・欲望·消費 (La femme dans le rôle de la femme: littérature, désir et consommation), Tokyo, Shin.yōsha 新曜社.

OKADA Emiko 岡田恵己子 2005 «Hiratsuka Raichō no bosei shugi feminizumu to yūsei shisō » 平塚らいてう の母性主義と優生思想 (Le féminisme maternaliste de Hiratsuka Raichō et le courant eugéniste), The Journal of Social Sciences and Humanities, Social Works, Tokyo Metropolitan University, 21 : 23-97.

OKANO Takeo 岡野他家夫 1952 «Seitō no sakka »『青靼』の作家 (Les auteures de Seitō), Kokugo to kokubungaku 国語と国文学, mars, 29 (3) : 22-33.

ŌKOSHI Aiko 大越愛子 2005

«Seitō ni okeru shoronsō 》『青鞜』に おける諸論争 (Les polémiques de Seitō), in Jendā no shiten kara miru nikkan kingendaishi ジェンダーの視点から見 る日韓近現代史 (Histoire moderne et contemporaine nippo-coréenne du point de vue du genre), Tokyo, Nashinokisha 梨の木舎, pp. 54-55.

Raichō kenkyūkai らいてう研究会 2001 Seitō jinbutsu jiten. Hyaku jūnin no gunzō 『青䩮』人物事典—110人の群像
(Dictionnaire des figures de Seitō. Portrait de 110 personnes), Tokyo, Taishūkan shoten 大修館書店.

SETOUCHI Jakuchō 瀬戸内寂聴 1984 Seitō 青鞜, 2 vols., Tokyo, Chūō kōronsha 中央公論社.

Shin feminizumu hihyō no kai

新・フェミニズム批評の会

(Association pour une nouvelle critique féministe) (éd.) 1998

Seitō o yomu『青靼』を読む (Lire Seitō), Tokyo, Gakugei shorin 學藝書林.

SUZUKI Yūko 鈴木裕子 [1986] 1997

Feminizumu to sensō フェミニズムと 戦争 (Le féminisme et la guerre), Tokyo, Marujusha マルジュ社.

TAKAMURE Itsue 高群冕枝 [1926] 1967 Ren.ai sōsei 恋愛創生 (Création de I'amour) in Takamure Itsue zenshū 高群逸枝全集 (Takamure Itsue. CFuvres complètes), vol. 7, Tokyo, Rironsha 理論社.

TAKEUCHI Ranko 竹内らんこ 1996 Manga Hiratsuka Raichō monogatari. Genshi, josei wa taiyō de atta まんが 平塚 らいてう物語——元始、女性は太陽であった (Manga, le récit de Hiratsuka Raichō. À l'origine, la femme était le soleil), Kyoto, Kamogawa shuppan かもがわ出版.

\section{UENO Chizuko 上野千鶴子 1998}

Nashonarizumu to jendāナショナリズム とジェンダー (Nationalisme et genre), Tokyo, Seidosha 青土社 (traduction anglaise, 2003 : Nationalism and 
Gender, traduit par Beverley Yamamoto, Melbourne, Trans Pacific Press).

WATANABE Mami 渡部麻実 2011

"Seitō to Burū sutokkingu »

『青鞜』とブルー・ストッキング (Seitō et les Bluestockings), in « Atarashii onna » kenkyūkai (éd.), op. cit.

YAMAKAWA Kikue 山川菊栄 1921

Shinfujin kyōkai to sekiran 新婦人協会と 赤瀾会 (L'Association de la femme nouvelle et la Société de la vague rouge), in Taiyō 太陽, juillet : 135-138.

\section{YAMAKAWA Kikue 1962}

«Seitō zengo oyobi Shinfujin kyōkai » 青鞜前後及び新婦人協会 (L'époque autour de Seitō et l'association Shinfujin kyōkai), in Shisō 思想, avril, 454 : 136-147.

YONEDA Sayoko 米田佐代子 1982

"Bosei shugi no rekishiteki igi » 母性主義の歴史的意義 (La signification historique du maternalisme), in Joseishi sōgō kenkyūkai 女性誌総合 研究会 (éd.), Nihon joseishi 日本女性史 (Histoire des Japonaises), Tōkyō daigaku shuppankai 東京大学出版会, 5 : 115-148. 